\title{
De dioses a humanos: cuidado, infancia y niñez entre el mundo prehispánico y el Nuevo Reino de Granada ${ }^{1}$
}

\section{From gods to humans: care, infancy and childhood between the pre-Hispanic world and the New Kingdom of Granada}

Natalia Montaño Peña ${ }^{2}$

DOI: 10.29151/hojasyhablas.n20a8

\section{Resumen}

El presente artículo es resultado de miradas y reflexiones acerca de la infancia y la niñez, y tiene como propósito comprender y aportar conocimiento acerca de sus trayectorias, tomando por caso el tránsito entre el mundo prehispánico y Virreinato del Nuevo Reino de Granada, con el cuidado como categoría eje. Para ello, como punto de partida, se precisa en la distinción entre infancia, niñez y sus modos de relación. Luego, se expone la concepción de cuidado desde la cual se hace el análisis y observación de las narrativas históricas. Finalmente, se plantean algunas consideraciones para continuar trabajando en investigaciones futuras. En todo ello, se muestra el vínculo con la religión y las deidades como elementos partícipes en la configuración de relaciones de cuidado.

Palabras clave: niñez; cuidado; religión; mundo prehispánico; Nuevo Reino de Granada.

\begin{abstract}
This paper is the result of views and reflections about infancy and childhood, and its purpose is to understand and contribute to their trajectories, taking as a case the transit between the pre-Hispanic world and the Viceroyalty of the New Kingdom of Granada, being "care" the axis. For this, as a starting point, it is necessary to distinguish between infancy, childhood and their relationship. Then, the category of care is exposed from a historical perspective. Finally, some considerations are raised to continue working on future research. In all this, the link with religion and deities is shown as participating elements in the configuration of care relationships.
\end{abstract}

Keywords: childhood; care; religion; pre-Hispanic world; New Kingdom of Granada.

\footnotetext{
${ }^{1}$ Algunos datos presentados en este artículo se obtuvieron durante el desarrollo de la tesis de maestría titulada "Narrativas acerca de las prácticas de cuidado de niños y niñas: notas históricas de Colombia” sustentada en el año 2014 para optar al título de Magister en Investigación Social Interdisciplinar de la Universidad Distrital Francisco José de Caldas. Sin embargo, las reflexiones comunicadas en este trabajo han tenido lugar a partir de experiencias de investigación posteriores y, principalmente, a partir de la consolidación de la tesis doctoral titulada "Construcción social de la infancia de la educación infantil en Colombia a través de la fotografía. 2006-2016” en la línea Comunicación-educación en la cultura del grupo de investigación Jóvenes, culturas y poderes del Doctorado Interinstitucional en educación, énfasis en lenguaje, de la Universidad Distrital Francisco José de Caldas, Universidad Pedagógica Nacional de Colombia y Universidad del Valle.

${ }^{2}$ Candidata a Doctora en Educación, Universidad Distrital Francisco José de Caldas. Correo: natamont_03@hotmail.com. ORCID: https://orcid.org/00000002-3643-7584
} 


\section{Introducción}

En algunas construcciones discursivas y medios de divulgación, es común encontrar las categorías infancia y niñez usadas indistintamente para hacer referencia al grupo de edad en la etapa inicial del desarrollo de la vida humana. En otros contextos, aparece también el término menor para señalar a un niño o niña. Esta última asociación, entre menor y niño y niña, se ubica en construcción y reproducción de la perpectiva adultocéntrica que otorga poder, dominio y acceso a los adultos sobre la acción, la acción, los bienes, modos de socialización y toma de decisiones de quienes son más jóvenes (Duarte, 2012).

Parece haber un consenso para estos usos de las categorías infancia y niñez; no obstante, no significan lo mismo. La infancia es una construcción social en torno, acerca de o con un grupo concreto de sujetos en relación con las estructuras sociales (Jenks,1982; James \& Prout,1997; Corsaro,1997), mientras que la niñez se refiere a los sujetos niños y niñas (Rodríguez, 2007) con características diversas, con narrativas propias y unos modos particulares de hacer presencia en el mundo (James \& Prout,1997).

Infancia y niñez se vinculan. La primera, es institucional; la segunda, corresponde al plano de lo individual y lo subjetivo. Ambas están sujetas a condiciones sociales, culturales e históricas que se imprimen en las representaciones de niños y niñas en una época y contexto específicos (Montaño, 2020). La infancia, en tanto construcción, es dinámica: cambia, se renueva y a su vez también lo hacen el conjunto de ideas a su alrededor, sus formas de ser narrada, y por supuesto, los modos de ser mirada. Al respecto, es importante recordar que el sentimiento moderno de la infancia (Ariès, 1987) se develó a partir de la observación y seguimiento a productos culturales que permitieron conocer cómo se iba dibujando en la sociedad una población no adulta. Por su parte, una amplia tradición disciplinar, discursiva, narrativa y de prescripciones ha buscado caracterizar lo que es y debe ser un niño o una niña en una época, una sociedad y en una cultura concretas; factores que dieron lugar al discurso de la infancia moderna. Sin embargo, allí no queda definida ni la infancia ni la niñez. Por el contrario, es desde los estudios sociales contemporáneos que se ha comprendido su heterogeneidad y se ha reconocido la necesidad de explorar una variedad de métodos de investigación y objetos de cultura para la producción de nuevos conocimientos que recojan sus experiencias, vivencias y modos de significación.

En todo caso, las prácticas con niños y niñas se han transformado y quedado registradas en objetos que han sido y están siendo analizados para identificar tendencias, saturaciones y vacíos en las representaciones de la infancia (Montaño, 2020). De allí que sea preciso volver la mirada, no solo en el tiempo sino a lugares e instituciones como la comunidad, la familia, la religión y el Estado, para comprender las trayectorias y las miradas sobre la infancia y la niñez. Esto implica una aproximación a las creencias y modos de vida en los cuales se enmarcan las vidas de los niños y niñas, y una relectura.

En este artículo, la mirada se dirige a los hallazgos de trabajos en los campos de la antropología y la historia que documentan prácticas con niñas y niños de algunas culturas prehispánicas, principalmente del actual territorio mexicano (Castañeda, 1988., González, 1994., del Castillo Durán, 2004., Correa, 2004., Austin \& López, 2008., Romero, 2015) a resultados de trabajos realizados desde los campos de la historia y la sociología relacionados con prácticas desde y entre familia, infancia y niñez durante Nuevo Reino de Granada (Dueñas, 1997., Páez Morales, 2006., Rodríguez y Mannarelli, 2007) y a documentos, literatura y narrativas de la conquista (Cortés, 1985.,Parres, 2001), comprendiendo que, entre ambos momentos y lugares de la historia, hubo una serie de transformaciones culturales, políticas, sociales y religiosas con incidencia en los modos de nom- 
brar, ver y tratar a niños y niñas, y que desde allí hubo unas construcciones discursivas particulares acerca de la infancia. Así mismo, se reconoce que esos modos de enunciación hacen parte de las trayectorias de la infancia y la niñez en América Latina, y que han marcado unos hitos que hoy se constituyen en marcos de referencia para pensar y mirar las infancias contemporáneas.

\section{Entre cuidadores y sujetos de cuidado. Un lugar seguro para la infancia y la niñez}

La infancia como discurso/lugar/objeto/ de estudio ha sido preocupación de una larga tradición de disciplinas con una marcada tendencia a homogenizarla, identificando diferencias entre los niñas y las niñas a través de la edad, la clase social o el género, principalmente (Amos Comenio, 1986., Rouseau, 1982., Pestalozzi, 1988., Montesori, 1982., Froebel, 2015., Piaget, 2015., Vygotsky, 2000., Kohlberg, 1992., entre otros). Los sujetos de la infancia han sido ubicados en espacios concretos de socialización como la iglesia, la escuela, la familia, la clínica, centros de protección e instituciones judiciales, hecho que ha permitido que a los niños y niñas se les haya tratado, e incluso se les haya definido, como seres incompletos, carentes, débiles en su carácter y en su físico, que deben ser preparados, por los adultos, para el futuro. En esta perspectiva, los niños y niñas han sido abordados como sujetos necesitados de cuidado, y desde allí se han construido toda clase de relatos religiosos, jurídicos y teórico-investigativos. Con dificultad, niños y niñas han llegado a ser vistos y tratados como sujetos con agencia, capaces de cuidar, crear y transformar (Gaitán, 2006; Bustelo, 2011).

Existen dos tipos de cuidado: el cuidado como virtud y el cuidado como relación (Comins, 2009). El primero, indica la cualidad y predisposición de un sujeto a brindar cuidado y atención a otro, como una tendencia de su carácter. Por su parte, el cuidado como relación implica la sensibilización de un sujeto ante la necesidad de atención a otro. Ambos tipos de cuidado no se oponen entre sí, más uno no conduce necesariamente al otro: si bien el cuidado como virtud puede llegar a nutrir una relación de cuidado, no es indispensable ya que en las relaciones de cuidado lo fundamental es dar y recibir atención en respuesta a la responsabilidad con las necesidades, sufrimientos y demandas, más no por el deseo mismo de cuidar (Noddings, 2002).

Cuidar es una acción que emerge del compromiso con el bienestar del sujeto objeto del cuidado (el cuidador). Esto significa la inaceptabilidad del cuidado cuándo es generado a causa del cumplimiento de una ley o norma y no por el deseo de responder a un compromiso con el otro, lo cual implica salir del propio marco de referencia, despojarse por un momento de las cargas propias y abandonar las necesidades de sí para para desplazarse y buscar sentir como está haciendo el otro, desde su propio marco de referencia (Noddings, 2003). En una relación de cuidado, la atención no se brinda por capricho, o por el deseo mismo de cuidado: el foco de la atención son las necesidades $\mathrm{y}$ las emociones en torno a ellas.

En esa perspectiva relacional, los sujetos involucrados (cuidador y cuidado) son sujetos activos y comprometidos con el cultivo de la relación. No hay edad mínima ni condiciones más allá de establecer el vínculo y lograr el desplazamiento ético a las necesidades, deseos y expectativas del otro, para su satisfacción, sin que ello implique un daño o pérdida a alguno de los involucrados. Así, es posible comprender el papel protagónico de niños y niñas no solo como sujetos "receptores" de cuidado, sino como sujetos activos capaces de disfrutar del cuidado que se les brinda, pero también en total competencia de brindarlo a sus pares, a los adultos, a los otros.

Al revisar la historia de diferentes pueblos -y reconociendo que la historia es una construcción mediada por intereses, posiciones, perspectivas, puntos de vista; que el historiador toma una serie de decisiones desde condiciones ideológicas, 
políticas y se permite ciertas libertades, por lo cual los hechos contados son producto de la reunión de elementos reales e imaginados (White, 2003)se encuentra evidencia de que antes de la intervención discursiva moderna de la infancia, en algunos contextos la niñez gozaba de una serie de privilegios y poderes que se fueron transformando y desvaneciendo con el paso del tiempo y hoy en día se intentan recuperar. De igual manera, se encuentra que aunque se declaraba y divulgaba un absoluto compromiso con niños y niñas, e incluso se juraba su cuidado, la realidad mostraba un total desapego y vulneración de sus cuerpos, sus necesidades y sus vidas.

\section{Entre protectores y dioses del mundo prehis- pánico: infancia, religión, comunidad y familia}

En Mesoamérica prehispánica, el bienestar de los niños y niñas era una prioridad de las comunidades. Austin (2006 citado en Rodríguez y Marianelli, 2007) encontró que, entre los antiguos Nahuas la infancia se reconocía como la edad en la que los individuos (los niños y las niñas) estaban expuestos a los mayores peligros de orden natural y sobre natural, más su presencia era un regalo divino, una recompensa de la madre tierra y la garantía de la continuidad de la vida. Diferentes comunidades tuvieron dioses cuyo poder se manifestaba a través del dar, preservar y cuidar la vida de los niños desde el momento mismo de su concepción. Divinidades como Tonantzin, Pacha Mama, Bachué o Tlazolteotl ${ }^{3}$, eran las deidades que proveían la vida, protegían a las madres durante la gestación, el parto, la crianza y cuidaban a los recién nacidos de enfermedades, maleficios, accidentes y catástrofes (Rodríguez y Mannarelli, 2007). A manera de ilustración, se documenta:

A Tlazoltéotl, la diosa madre en la cultura nahual se le representa en actitud de parir, de la forma en que el parto se ha representado en las diosas de las culturas más antiguas. En cuclillas y con las palmas de las manos en las nalgas, un gemido sale de su boca semiabierta en tanto que de su bajo vientre emerge la cabeza de un recién nacido. Esta figura así representada, muestra la forma en que la mujer prehispánica daba a luz, con la fuerza de su cuerpo y su mente, viendo hacia el infinito como pidiendo la ayuda de los dioses en el difícil momento de traer a un nuevo ser a la vida (Correa, 2004, p.12).

En algunas culturas, además de estas formas de la gran diosa dueña del poder de la creación, existían otras divinidades, cada una ocupada de brindar un cuidado especifico: Acat, creador de los infantes en el vientre materno; Teopclzintli, el dios del niño; Tzinteótl, diosa de madres gestantes y recién nacidos; Xoaltícitl, diosa cuidadora del sueño de los niños; Piltzintecuhtli, cuidador los niños hijos de nobles; Temazcalteci, diosa de la salud de los infantes, entre otros. De igual manera, existió en la cultura azteca "un ser humano que encarnaba los poderes para curar a los niños" (Rodríguez y Mannarelli, 2007: 55). Su nombre era Ixtlitlton, el "carinegrillo". En esta tradición, el arte de curar a los niños era una práctica altamente valorada, muestra de sabiduría.

Además de los dioses protectores de la infancia, gracias a las Crónicas de Indias se conoce el importante papel de la partera, mujer sabia dedicada a traer niños y niñas al mundo (Romero, 2015). En estas crónicas se expresa que la noticia de un embarazo era motivo de celebración a través de un ritual en el cual la mujer preñada era presentada oficialmente a la comunidad, y un orador la encomendaba a la gran Diosa de la vida y en ese mismo momento, la familia invitaba a la embarazada a mostrar "humildad y gratitud" y le exigían cuidar a su bebé desde ese mismo instante. Como acto de vigilancia y muestra de una cultura del cuidado prenatal, en estas comunidades no era suficiente la atención al bebé por la madre y su fa-

${ }^{3}$ Estas divinidades era distintas representaciones de la Madre Tierra y otras diosas de la fecundidad. 
milia. Cuando se acercaba el momento del alumbramiento, tenía lugar un segundo ritual en el cual se escogía a una partera, "mujer sabia", "persona honrada y digna de veneración" a quien se le hacia la siguiente suplica:

(...) os rogamos señora, que hagáis misericordia con esta muchacha y que hagáis con ella vuestro oficio y facultad, pues que nuestro señor os ha hecho maestra y médica, y por su mandado ejercitáis este oficio [...] Déos Dios muchos días de vida para que le sirváis y ayudéis en este oficio que os ha dado" (Rodríguez y Mannarelli, 2007, p. 32).

Estas palabras eran el preámbulo a un pacto de responsabilidad de la partera con el bienestar de la madre y su hijo. Una vez esta mujer se comprometía a atender a la madre, se iniciaba una etapa de acompañamiento y orientación. Llegado el momento del alumbramiento, la partera bañaba a la madre y la alentaba en el trabajo de parto. Si el parto se retrasaba, la partera suministraba a la madre hierbas medicinales para evitar la muerte del bebé, y si era necesario adoptaba actitud de oración para pedir la intervención divina (Correa, 2004). Todo el tiempo se encargaban los bebé a los dioses, entre otras razones, porque también se creía que, seres maléficos empeñados en impedir el crecimiento de un pueblo atentarían contra las gestantes, de ahí que la naturaleza, en su infinita sabiduría, escondía a los bebés en el vientre materno, como cofre de un tesoro (Castañeda, 1988).

En el mundo prehispánico había toda una red de cuidado prenatal y del neonato siempre en cabeza de los dioses y conformada por mujeres cultivadas, formadas, preparadas para garantizar la sana formación del bebé dentro del vientre materno, junto con la familia y el cuerpo de la comunidad. Una vez la partera cumplía con su cometido, la familia y la comunidad asumían el cuidado del recién nacido y poco a poco lo hacían partícipe de los asuntos propios de la comunidad, como la preparación para los oficios (agricultura, escultura, orfebrería o la guerra), asegurando así su bi- enestar y del pueblo con los servicios retribuidos.

La relación de cuidado era amplia: eran varios los sujetos involucrados en el cuidado y se buscaba garantizar la reciprocidad entre los niños, las niñas y su comunidad.

Abordar la infancia protectora de un pueblo o una comunidad no es asunto sencillo de comprender. No extraña que hoy en día, a pesar de tantos hallazgos y revisiones a ciertas prácticas del mundo prehispánico, se sigan emitiendo juicios de valor de rechazo tal como sucedió cuando los cronistas describían el Nuevo Mundo (Del castillo Duran, 2004). Esto sucede porque las lecturas se hacen fuera de contexto y no se recupera en la lectura el fin último, el para qué de los sucesos. A la luz de la teoría del cuidado, frente a estos hechos se encuentra que no se trataba de un ejercicio de cuidado como virtud, sino de una relación de cuidado mutuo.

Los niños, desde el momento mismo de su nacimiento, adquirían una responsabilidad de lealtad y defensa de su comunidad. Ya fuera a través de modificaciones corporales, o de los sacrificios infantiles, ellas y ellos debían estar dispuestos a ofrecerse en sacrificio religioso por voluntad de los dioses y recuperar el equilibrio cósmico (González, 1994). El códice mendocino (1540) es prueba de la función redentora adjudicada a los niños en la cultura azteca, en donde existían diferentes formas de dar muerte a los menores. La investigadora Parres (2001), en su análisis de la iconografía azteca, encuentra que:

Los niños llenaban otra función muy importante en esta cultura: la de ser sacrificados a los Dioses. Los que se ofrecían a Tlaloc, morían ahogados. Anestesiaban con yautli a los que se ofrecían al Dios del fuego y luego morían quemados sobre un brasero. Los de Xipe/totec, morian azotados, después eran desollados para que los sacerdotes vistieran su piel. Se pensaba que eran mensajeros que se enviaban a los Dioses revestidos de una dignidad casi divina (Parres, 2001, p. 93). 
El sacrificio humano, específicamente el infantil, tenía una función social redentora y salvadora, pues tenía lugar cuando se perseguía el bien común de los pueblos. Sin embargo, la mirada desde afuera era muy distinta, y los dioses fueron rebajados al nivel de ídolo, por lo cual, estos sacrificios fueron vistos como abominables. Al respecto, en las Cartas de la conquista de México (Cortés, 1985) se narra la práctica de sacrificios infantiles con las siguientes palabras:

... todas las veces que alguna cosa quieren pedir a sus ídolos, para que más aceptación tenga su petición, toman muchas niñas y niños y aún hombres y mujeres de más mayor edad, y en presencia de aquellos ídolos los abren vivos por los pechos y les sacan el corazón y las entrañas, y queman las dichas entrañas y corazones delante de los ídolos, ofreciéndoles en sacrificio aquel humo. Esto habemos visto algunos de nosotros, y los que lo han visto dicen que es la más terrible y más espantosa cosa de ver que jamás han visto. Hacen estos indios tan frecuentemente y tan a menudo, que, según somos informados, y en parte habemos visto por experiencia en lo poco que ha que en esta tierra estamos, no hay año en que no maten y sacrifiquen cincuenta ánimas en cada mezquita, y esto se usa y tienen por costumbre desde la isla de Cozumel hasta esta tierra adonde estamos poblados; y tengan vuestras majestades por muy cierto que, según la cantidad de la tierra nos parece ser tan grande y las muchas mezquitas que tienen, no hay año que, en lo que hasta ahora hemos descubierto y visto, no maten y sacrifiquen de esta manera tres o cuatro mil ánimas ... (Cortés, 1985, p.20).

Los niños expuestos a este tipo de rituales no siempre eran miembros de la misma comunidad. Existieron guerras cuyo fin último era capturar personas de otros pueblos, entre ellas niños, para extraerles el corazón, acto que agradaba al dios sol. Esta práctica fue común entre los Aztecas, y en algunos casos esporádicos lo hicieron también los Muiscas. Así, encontramos las Guerras Floridas o Guerras Santas, en lengua nahual Xochiyaoyotl. Se llamaban así, porque el corazón humano era asociado con flores y el propósito de estas guerras era obtener cuantas flores fuera posible. Los sacrificios no se daban en el momento mismo de las batallas, sino que para ello existía un ritual. Los enfrentamientos eran pactados entre dos pueblos para obtener víctimas que luego serían sacrificados en un ritual al sol (Austin; López, 2008). Luego, los rehenes eran alimentados, atendidos, cuidados y finalmente incluidos en las ceremonias de sacrificio en dónde se les extraía la flor del movimiento: el corazón.

En el mundo prehispánico, cuidar a un niño era ante todo un deber con el cosmos, un pacto para la garantía de la vida de un pueblo, y sacrificarlo era un acto vital para mantener el orden de las cosas. En general, los sacrificios infantiles, tanto en rituales de paso como en contextos de guerras, encerraban un carácter religioso, cosmogónico y divino. Durante los sacrificios, los niños dejaban de ser seres individuales, para representar a un pueblo en el intercambio de vida por más vida, fortuna y bendiciones.

\section{Del cuidado como compromiso al cuidado se- lectivo: un Dios y un nuevo lugar para niños y niñas durante la colonia neogranadina}

La conquista de América trajo consigo dramáticas implicaciones para las culturas prehispánicas. Los pueblos indígenas vivieron drásticos cambios en su organización, económica, política, religiosa, social y, naturalmente, familiar. La colonia se tradujo en un largo derramamiento de sangre, mientras se logró la instalación de la cultura europea de finales del siglo XV. El modelo social hispano dictado por la Iglesia católica asumió la supresión de los modos de vida de las comunidades nativas para cristianizar al mundo, hecho que derivó en la precarización de la vida de quien mostró resistencia. En este contexto, la concepción de familia fue transformada durante la evangelización. El proceso inició con la aceptación de un único dios verdadero y la institucionalización de matrimonios católicos. La presencia de la Igle- 
sia implicó el desarraigo de las creencias religiosas existentes, motor de la vida prehispánica.

Con la familia intervenida, la concepción de infancia sufrió una violenta transformación: los niños nativos pasaron de ser protectores en contacto directo con sus dioses, a ser individuos foco de evangelización (de León Azcárate, 2015). Para el mundo cristiano, estos niños fueron criaturas a bautizar para borrar su pecado original. Así, los sacrificios infantiles de orden sagrado fueron sustituidos por prácticas de control social. Muchos niños y niñas fueron alejados de sus familias para recibir educación cristiana o fueron reclutados para el trabajo.

A partir del siglo XVI, la niñez resultó ser igual de invisible que en la Europa medieval. Si bien, tenían presencia en todas partes, se perdían en el paisaje. En palabras de la historiadora Dueñas (1997):

Los niños estaban en todas partes: en los talleres de los artesanos aprendiendo un oficio, en las pulperías haciendo mandados, en la huerta y la cocina al lado de la madre, y compartiendo la habitación donde los padres comían y dormían. Los niños y jóvenes aparecen constantemente en los testamentos, en los pleitos sobre alimentos, en las tutorías y en las herencias. A pesar de su omnipresencia, o posiblemente debido ella, rara vez se les describía (p. 188).

Si bien, la niñez nativa fue invisibilizada durante la colonia, es posible rastrear el estado de los niños y niñas en los documentos legales de la época, que determinaron modos de ver a la infancia, clasificarla y legitimar prácticas de cuidado hacia ella. Por ejemplo, en las Siete Partidas (Alfonso X, 1256 y 1263), cuerpo normativo que reguló la vida pública y privada de la época, niños y niñas fueron clasificados para ordenar sus pautas de crianza, según ascendencia racial. Si bien el documento fue redactado en la Edad Media, rigió al mundo hispano durante varios siglos, llegando así a las colonias americanas. Según estas, solo los hijos del rey podían lograr el lugar de infantes ${ }^{4}$ y ser tratados como tales.

A diferencia de España, en América colonial todos los menores de edad eran nombrados 'párvulos' o "parvulitos" si eran muy pequeños (Dueñas, 1997). En estas sociedades, debido a las circunstancias de mestizaje, en muchos casos forzado a la clasificación de los niños, tuvo lugar en el plano de la legitimidad e ilegitimidad, marcando los modos de socialización de niños y niñas, sus derechos, cuidado y protección que por ley merecieron, así como el nombramiento legal de quienes debían responsabilizarse por ellos. Las Partidas definieron como legítimos a los hijos nacidos de matrimonios reconocidos por la iglesia católica. Así, ellos eran bienes del matrimonio, y de acuerdo a la ley:

... tienen las honras de sus padres, y otrosí pueden recibir dignidad y orden sagrada de la iglesia, y las otras honras seglares. Y aun heredan a sus padres y a sus abuelos y a los otros sus parientes, lo que no pueden hacer los otros que no son legítimos (Alfonso X, Título 13, Ley 2).

Entre la sociedad no noble fueron difusas las leyes que protegían a la niñez y mucho más visibles los deberes de los menores hacia sus padres y su comunidad. Las condiciones de amor y protección de hijos a padres debían darse por razones de agradecimiento. Por su parte los padres, aunque la ley dictaba que debían procurar lo mejor para sus hijos, y aun cuando la voluntad se los impi-

\footnotetext{
${ }^{4}$ Infantes se llaman en España a los hijos de los reyes, y ellos deben en sí ser nobles y de buenas mañas y sin ninguna maldad, por razón de la nobleza que les viene de parte del padre y de la madre; y tomaron este nombre de infantes, que es palabra del latín que quiere tanto decir como mozo, menor de siete años, que es sin pecado y sin mancilla. Y por eso deben los reyes hacer porque sean sus hijos tales y amarlos mucho (Partida II, título 7, Ley 1)
} 
diera, eran más fuertes sus derechos como padres que los de sus hijos y estaban en la obligación de impartirles castigos que condujeran a la corrección del comportamiento. Esta libre vía sobre los menores hizo lícita la total vulneración de sus cuerpos durante la colonia; no obstante, la ley tuvo que contemplar castigos para los padres y parientes que abusaban de su poder y ponían en peligro la vida de los menores. Así el castigo derivara en homicidios, la ley dictó que:

El padre tiene derecho a castigar mesuradamente a sus hijos, así como el señor a su siervo, y el maestro a su discípulo. Mas, para evitar los abusos que en esta materia se comete, si alguno de ellos se sobrepasa y alguno muriera, se condenará al agresor a pena de destierro por cinco años. Si las heridas las hiciere con intención de matar, será condenado con la misma pena de los homicidas (VII P, T. VIII, LIX). Cuando sea el padre quien mata a su hijo o viceversa, o el abuelo al nieto o bisnieto, o el hermano a su hermano, tío al sobrino, el marido a la mujer y, en general, entre quienes tengan algún grado de parentesco, sufrirá un castigo no sólo peculiar, sino extremo: además de la pena de azotes, la muerte por inmersión en el mar en un saco donde se hayan colocado animales (P. VII, T. VIII, L. XII) (Páez Morales, 2006, p.52).

Muchos castigos solían terminar con la vida de niños. Sin embargo, en los archivos de crímenes no abundan los testimonios de estos hechos, más en hogares no nucleares, en los cuales se criaban los hijos ilegítimos. Ellos, en cuestión de beneficios, eran puestos al margen de lo dictado por la ley. Sus restricciones y posibilidades en la sociedad eran determinadas según las circunstancias de su concepción, la raza de sus padres y su condición económica (Dueñas, 1997; Morales, 2006). Así, dentro del título de hijos ilegítimos existió una clasificación de acuerdo a estos criterios: Los naturales, hijos de mujeres amantes; los fornecidos y notos, hijos producto del adulterio; manceres, hijos de prostitutas; espurios, hijos de mujeres promiscuas; Incestuoso, hijos de padres parientes (Partida IV; Páez Morales, 2006). Según ordenaba la ley, ellos solían permanecer junto a su madre durante sus primeros 3 años de vida; una vez superada esta edad, los niños podían estar en manos de cualquier persona.

En Santafé, capital del Nuevo Reino de Granada, los hijos ilegítimos vivían en hogares múltiples o extendidos y no contaban con un cuidador concreto, pues cualquier persona o ninguna, según disposición, podía cuidar de ellos. Esta situación se prestaba para crímenes infantiles tales como golpizas o acceso carnal violento, generalmente hacia las niñas (Dueñas, 1997). En la vida de estos niños, el vínculo padre e hijo -cuando tenía lugar- era intermitente. La paternidad se ejercía según permitiera la voluntad del adulto y no las necesidades del niño. Ante la falta de un reconocimiento legal, la brutalidad en los castigos era más notoria. Solo cuando los castigos llegaban al rango de brutalidad se hacían visibles en los tribunales. A manera de ilustración:

Hay un caso que no pasó desapercibido debido a su extrema crueldad y a las circunstancias especiales en que ocurrió. Se trata de un pequeño de entre seis y siete años que fue encontrado en el zaguán de la casa de una señora santafereña y que presentaba graves quemaduras en sus piernas y genitales, además de señales de haber sido azotado con sevicia. El chiquillo, que se hallaba entre la vida y la muerte, fue llevado a la casa de la dama salvadora. El padre de la víctima fue llamado a los tribunales a responder por su conducta. Por sus declaraciones, sabemos que el niño era hijo natural y que pasaba temporadas en casa de su padre, el cual estaba casado con otra mujer distinta a la madre del niño. Esta última, al momento del atropello, no estaba en la ciudad. El padre declaró haber amenazado con quemarlo por "haber tomado el vicio de huirse de la casa". Dijo que lo amarró "sólo de una mano" y prendió fuego a un "poquito de paja" para quemarle los pies, pero que el chico comenzó a dar saltos para soltarse de sus ataduras y esa fue la causa de que se hubiera quemado (Dueñas, 1997, p. 193). 
La ilegitimidad en muchos casos justificaba la precariedad, maltrato y extrema vulnerabilidad de la niñez. Al igual que los niños y niñas en extrema pobreza, bastardos o hijos de padres divorciados, los niños ilegítimos eran comúnmente abandonados. En el año 1636, el Rey de España recibió una carta del Presidente de la Audiencia de la Nueva Granada en dónde se ordenó a los Hermanos de San Juan de Dios recoger en el hospital a los niños abandonados. La situación de los niños era alarmante, al punto que el Rey en su respuesta usa las siguientes palabras:

...he entendido la impiedad que se tiene en ese reino con los niños expósitos y especialmente en esa dicha Audiencia, que esto es en tanto grado, que no sólo los indios, sino también los españoles tienen por costumbre de exponerlos en acabado de nacer en las calles públicas, en las puertas y puentes y otras partes solitarias donde son comidos y despedazados de perros y otros animales, padeciendo en esto los inocentes y quizá sin agua de bautismo... (Páez Morales, 2006, p. 180).

Años más tarde el panorama no mejoraba y las noticias del alto índice de abandono en la capital generaron en la Corona Española una comunicación oficial a la Audiencia de Santa Fé en 1639:

... por la impiedad [...] no sólo [de] los indios, sino de los españoles [se había hecho] costumbre exponerlos en acabado de nacer en las calles públicas, en las puertas y puentes solitarios donde [eran] comidos y despedazados por los perros y otros animales, padeciendo en esto los inocentes y quizá sin agua de bautismo (Rodríguez y Mannarelli, 2007, p. 265).

Así, a través de la Cédula de 7 de diciembre de 1639, se creó en la capital del Nuevo Reino una casa para "acoger y criar los niños expósitos" y a las mujeres abandonadas por sus esposos o que permanecían en la indigencia, llamada la casa de expósitos y recogidas. En la casa los niños no estaban solos. Compartían espacio con ancianos, mendigos y vagos. Las instituciones de este tipo quedaron a cargo de la Iglesia y del Estado. Se sostenían a partir de las limosnas, principalmente, y estos espacios se convirtieron en los lugares de socialización de niños y niñas indeseados. No obstante, había requisitos para poder estar allí: se solicitaba a las madres que abandonaban a sus hijos dejarlos en la puerta de la casa con una nota en donde constara si el niño estaba bautizado o no, pues el bautizo era requisito para el servicio de protección y cuidado. Si el niño no se encontraba "en el libro de los hijos de Dios" la casa corría con los gastos y trámites para el sacramento. Su crianza y sus destinos dependían del color de la piel (Morales, 2006).

Una vez adentro, los niños estaban a cargo de mujeres reclutadas a modo de presidiarias para amamantar a los niños por un pago de 2 pesos al mes. Las cuidadoras, o llamadas de manera despectiva "las mitas lecheras" no recibían ninguna orientación de cuidado, aún cuando tenían a su cargo dos o tres niños. Se confió en su instinto maternal, aunque la mayoría eran madres primerizas y solteras. Estaban bajo el mando de una religiosa, sin conocimiento alguno de maternidad (Dueñas, 1997; Morales, 2006; Ramírez, 2006). Sumado a la ausencia de capital humano suficiente para el cuido, estaba el problema de higiene y salubridad. Las mujeres en la casa eran pocas, y si cuidaban a niños y niñas no podían hacerse cargo del orden y aseo de la casa, incluyendo la higiene propia, lo que desató enfermedades transmitidas por la leche.

Recapitulando, en esa época niños y niñas eran clasificados y tratados según la legitimidad de su concepción. La ley ordenaba unas normas mínimas de cuidado de los padres a los niños legítimos, permitiendo ciertos castigos para formar su conducta y carácter, pero con los niños ilegítimos las normas de protección eran más difusas. Los niños indeseados (ilegítimos, pobres, bastardos, naturales) eran abandonados en las calles y, para no morir de hambre o frío, algunos de ellos eran trasladados a instituciones protectoras regu- 
ladas por el virreinato y la iglesia, en donde se les exigía el bautizo para ser atendidos. Allí, recibían alimento de mujeres sin experiencia en cuidado infantil y debían someterse a condiciones mínimas de aseo e higiene, no obstante, era mucho mejor que estar en la calle. De este modo, el cuidado se delegaba entre unos y otros, o se imponía, no había una red ni garantía de la atención necesaria ni satisfacción mínima de sus necesidades. En otras palabras, eran precarias las prácticas de cuidado a la niñez.

Otra institución con un propósito similar fue El Hospicio Real creado en 1790 con el propósito de ejercer mayor control sobre la sociedad, concentrando en un solo lugar a la población marginal, las mujeres con asuntos pendientes ante la ley y los niños que nadie quería tener. En esta institución prestaban servicios de cuidado y amamantamiento las mujeres nativas y africanas recluidas, junto con las mujeres abandonadas por sus maridos quienes mientras esperaban la repartición de bienes debían asegurar para ellas y para sus hijos la ración de comida diaria, y las mujeres pobres que preferían dejar de amantar a sus hijos para ganar algo de dinero. En este contexto, el cuidado de los niños tampoco fue voluntario, sino que se trató de un servicio asistencialista prestado por obligación o necesidad económica (Dueñas, 1997; Rodríguez y Mannarelli, 2007).

Por lo anterior, los índices de mortalidad en el Hospicio fueron altos, algunos de los registros de los decesos se encuentran hoy en el Archivo General de la Nación y señalan:

la mortalidad en Santafé era extraordinaria. De los 33 niños que tenían amas de cría en 1767 , murieron 12 en el curso de pocos meses. En 1810 la situación empeoró, ya que el 41 por ciento de los niños asignados a las amas de cría murieron a los pocos días o en el curso de los primeros meses. Sólo uno de los niños murió después de haber cumplido su primer año de vida (como se citó en Dueñas, 1997, p. 199).
Tanto la Casa de niños abandonados y mujeres recogidas como el Hospicio Real de Bogotá fueron instituciones que guardaron a los niños del hambre y del frío, pero estuvieron expuestos a enfermedades, maltrato y explotación. En estas instituciones los niños no estaban solos. Compartían espacio con ancianos, mendigos y vagos. A manera de ilustración, un documento encontrado en el Archivo general de la Nación por Morales (2006) señala:

Los viejos, a quienes el peso de los años los ha agobiado, haciéndoles Imposible el sustentarse y vestirse con el sudor de su rostro, cuyos auxilios con los espirituales allí se les prestan misericordiosamente no menos que a otros impedidos por accidentes incurables, que les han sobrevenido. Allí también son auxiliados niños, y mozos, que entregados a la holgazanería se dedican a pedir limosna, huyendo de toda ocupación para ser polilla de la sociedad, porque al ocio se sigue todo género de vicios, y en los hospicios se les obliga al trabajo de las artes, con que se hacen útiles, ya que reciban una educación cristiana instruyéndose en los rudimentos de nuestra Santa Religión y frecuentando los sacramentos... (Morales, 2006, p. 184).

Estos niños no conocieron ni el afecto ni cuidado integral. Su protección fue la justa para no morir apenas nacidos, pero sí antes de cumplir el primer año. Muchos entraban, pero pocos lograban superar los 5 años. Ante su difícil situación, en la primera mitad del Siglo XIX el Rey de España concede a estos niños:

la legitimación y el poder gozar de los privilegios que gozan los legítimos para todos los efectos civiles; han de quedar en la clase de hombres del estado llano general, ser admitidos en los colegios de pobres, Casas de Huérfanos y otras similares, con opción a las dotes destinadas a los pobres; ser protegidos por las autoridades civiles para no ser discriminados a causa de su condición; no deben ser sometidos a la pena de vergüenza pública, azotes ni horca, quedando sometidos al mismo régimen de penas que se 
impondría a las personas privilegiadas. Los expósitos pueden, además, acceder a la profesión monástica, aunque para el caso de América no se les permite obtener ciertos curatos y prebendas del Real Patronato" (Páez Morales, 2006: 190).

Con esta declaración, niños y niñas en esta condición obtuvieron beneficios, un apellido, acceso a la educación formal y un lugar de reconocimiento en la sociedad neogranadina, con el cual garantizaban el respeto a sus vidas y unas prácticas de cuidado a cargo de instituciones especializadas para ellos y de las hermanas de la caridad. Este, junto con otros sucesos, permitieron que al final de la Colonia e inicios de la República los niños en condición de vulnerabilidad obtuvieran unas incipientes garantías de cuidado y protección. No obstante, no se puede perder de vista que antes de la colonia las condiciones de la infancia en el territorio eran más adecuadas.

\section{Para continuar por el camino de la infancia y la niñez}

Las narrativas, representaciones y modos de nombrar y mirar la infancia que aquí se han presentado son solo una pequeña muestra de las prácticas de cuidado de las cuales eran protagonistas los niños y las niñas en un momento de la historia. Es necesario insistir en que cada una de ellas debe ser leída y abordada en contexto, de lo contrario no se podrá hacer un ejercicio comprensivo de las trayectorias de la infancia y la niñez. Y también es importante conocer estas narrativas de la historia para plantearse nuevos problemas de investigación.

La creciente preocupación por la infancia en la niñez es producto de siglos de buenas y malas prácticas, de maltrato, vulneración, abandono e invisibilidad. Volver la mirada en el tiempo permite conocer los antecedentes a toda una trayectoria de normativas y políticas que han buscado solucionar problemas que permanecen. Por desconocimiento, se puede caer en la trampa de implementar los mismos métodos esperando resultados diferentes, y de eso, en relación con la infancia ha habido bastante. En muchos aspectos se ha avanzado frente al reconocimiento de la infancia y la defensa de la niñez, no solo en Colombia, sino en América Latina; pero en pleno siglo XXI no se ha logrado la garantía plena de los derechos de niños y niñas, tema que se espera sea el objeto de análisis de otro trabajo.

\section{Conclusiones}

Al volver la mirada al mundo prehispánico, se encuentra un tejido de relaciones entre dioses y humanos para el cuidado y protección de niños y niñas, así como una construcción de la infancia como garantía de la continuidad de la vida, por lo cual participar en su cuidado era un acto de honor y gratitud. Luego, con la conquista española de los territorios americanos, y el impacto que ello implicó en la religión y la sociedad, en la cultura en general, la nueva concepción de familia y la condición de bautizarse en señal de reconocer un único dios, adquirir un alma y someterse a un rey, la niñez fue clasificada, la infancia transformada y las prácticas de cuidado resignificadas.

Estas narrativas históricas ponen en evidencia que desde hace varios siglos el cuidado, protección y bienestar de niños y niñas ha requerido la intervención legal, cultural, política y religiosa, de modo que no son ni una preocupación menor ni producto de las formas de conocer y razonar modernas. Desde antes de que las disciplinas nombraran y perfilaran a los niños y las niñas, ya había todo un camino recorrido en la creación de redes de cuidado. Tan es así que, desde la antropología y los estudios sociales de la infancia hay líneas de investigación dedicadas a conocer las prácticas ancestrales para comprenderlas y, si es el caso, apropiarlas. 
También, se encuentra evidencia de que niños y niñas están en plena capacidad de cuidar de otros y de sí mismos, de modo que educar en el cuidado es una práctica ya cultivada. Primero, ellos cuidaban de pueblos enteros en una relación bilateral y de gratitud; luego, aprendieron a cuidarse entre sí, al interior de las instituciones protectoras, para no perecer. De ahí en adelante, son muchas más las experiencias que se puede rastrear y dan cuenta de la mirada tan limitada que se ha tenido de niños y niñas como sujetos dependientes.

La religión ha permeado las prácticas de cuidado entre, con y hacia niños y niñas, los ha expuesto a situaciones de riesgo; todo depende desde donde se lea. A su vez, ha contribuido en la construcción de discursos, representaciones, narrativas y prescripciones acerca de la infancia, y con ello ha intervenido en otras esferas como la normativa y la política. Finalmente, el cuidado de la infancia es un asunto de la vida pública y privada de una sociedad y no puede impartirse sin escuchar y conocer de primera mano las necesidades, capacidades y deseos de niños y niñas.

\section{Referencias bibliográficas}

Alfonso X. (1252). Las siete Partidas. Reino de España.

Ariès, P., (1987). El niño y la vida familiar en el Antiguo Régimen. Madrid: Taurus.

Austin. A; López L (2008). El pasado indígena. Colegio de México y F.C.E. México.

Bustelo, E. (2011). El recreo de la infancia: Argumentos para otro comienzo. Buenos Aires, Argentina: Siglo XXI Editores.

Castañeda. I. (1988). Síntesis histórica de la partera en el valle de México. Revista de enfermería, 11(1). Instituto mexicano de seguridad social. México

Comins. I. (2009). Filosofía del cuidar. Una propuesta coeducativa para la paz. Barcelona, España: Icaria Editorial.
Correa. M. (2004). Pariendo como diosas, maternidad indígena. Escuela Nacional de Antropología e Historia. México.

Corsaro, W. (1997). The Sociology of Childhood. SAGE Publications, Inc.

Cortés. H. (1985). Cartas de la conquista de México. Madrid, España: Biblioteca de la historia.

Del Castillo Durán, F. (2004). Las crónicas de Indias. Montesinos. España: Ediciones de intervención cultural.

De León Azcárate, J. L. (2015). La Biblia y la evangelización del Nuevo Mundo durante el siglo XVI. Veritas, (32), 195-227.

Dueñas. G. (1997). Los hijos del pecado, ilegitimidad y vida familiar en la Santafé de Bogotá Colonial. Bogotá, Universidad Nacional de Colombia.

Duarte, C. (2012). Sociedades adultocéntricas: Sobre sus orígenes y reproducción. Revista Última Década, 20(36), 99-125.

Gaitán, L. (2006). Sociología de la infancia: Nuevas perspectivas. Madrid, España: Editorial Síntesis.

González. Y. (1994). El sacrificio humano entre los mexicas. Sección de obras de antropología. $2^{a}$ edición de Fondo de Cultura Económica. México.

James, A. y Prout, A. (1997). Constructing and reconstructing Childhood. En Contemporary Issues in the Sociological Study of Childhood. London: Falmer Press.

Jenks, C. (1982). The Sociology of Childhood: essential readings. London: Gregg Revivals.

Montaño, N (2020). Construcción social de la infancia a través de imágenes y fotografías: una entrada a la educación. Ánfora, 27 (48), 67-92. DOI: https://doi.org/10.30854/anf. v27.n48.2020.669

Noddings, N. (2002) Starting at home: caring a social policy. University of California Prees. USA.

Noddings, N. (2003). Caring. A feminine approach to etics and moral education. Universidad de California Press. USA. 
Páez Morales, G. (2006). Familia, infancia y sociedad en la colonia neogranadina. Estudio sociológico e histórico. Bogotá, Universidad Santo Tomás.

Parres, A. (2001). La niñez en el códice mendocino. Escuela nacional de antropología e historia. México.

Rodríguez, I. (2007). Para una sociología de la infancia: Aspectos teóricos y metodológicos.
Madrid, España: CIS.

Rodríguez. P y Mannarelli. M. (2007). Historia de la infancia en América latina. Bogotá, Universidad Externado de Colombia.

Romero, V. (I semestre, 2015). La figura de la partera en las crónicas coloniales andina. Revista Runa Yachahiy, 10, Berlín. Recuperado de http://www.alberdi.de/coleccion2015.html

White, H. (2003). El Texto Histórico Como Artefacto Literario. Buenos Aires, Argentina: 